\title{
Percepção da saúde mental em policiais militares da força tática e de rua
}

KATYA LUCIANE DE OLIUEIRA

LUANA MINHARO DOS SANTOS*

\section{Resumo}

A vida laboral do policial militar está permeada por situações que envolvem estresse extremo. Esse fato pode gerar possíveis quadros de desequilíbrio emocional. Assim, explorar a percepção de policiais militares da força tática e de rua acerca dos aspectos que permeiam sua saúde mental foi o objetivo deste estudo. Participaram 24 policiais militares de dois Batalhões da Polícia Militar do Estado de São Paulo. Para aqueles que consentiram na participação, foi aplicado individualmente uma escala com 30 questões, abordando assuntos relativos ao tema. Os resultados evidenciaram que os participantes $(91,7 \%)$, sempre ou às vezes, percebiam-se estressados; uma parte $(41,7 \%)$ relatou já ter agido impulsivamente em alguma ocorrência; 88,3\%, sempre ou às vezes, se sentiam emocionalmente cansados após o dia de trabalho; $62,5 \%$ afirmaram que às vezes percebiam-se agressivos no trabalho; $20,8 \%$ já pensaram em suicídio e 8,3\% nunca se sentiam realizados com a profissão. Sugere-se a necessidade de novos estudos.

Palavras-chave: Cansaço emocional. Cansaço físico. Estresse no trabalho. Polícia militar.

\footnotetext{
* Psicóloga, mestre em psicologia pelo Programa de Pós-Graduação Stricto Sensu em Psicologia da Universidade São Francisco, doutora em Psicologia, Desenvolvimento Humano e Educação pela Faculdade de Educação da Unicamp/GEPESP. Professora adjunta doutora do curso de Psicologia/PPSIC e do Mestrado em Educação da Universidade Estadual de Londrina. ** Psicóloga Clínica formada pelo Programa de Graduação em Psicologia da Universidade São Francisco.
} 


\section{Introdução}

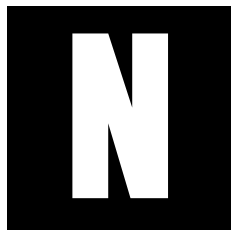

este artigo buscou-se refletir e discutir sobre a percepção que policiais militares têm acerca de sua própria saúde mental, tendo como base um levantamento exploratório e descritivo realizado com esses profissionais, no qual foi possível levantar algumas atitudes e opiniões que ilustram valores e formas de conduta. Os dados aqui apresentados serão discutidos à luz das contingências que o policial militar enfrenta no seu cotidiano laboral; também serão tecidas considerações que apontam para um conjunto de práticas que são reproduzidas historicamente na corporação militar e que, possivelmente se relacionam à saúde mental desse profissional.

No Brasil, a segurança pública sofre com uma realidade que remete ao crescimento contínuo das diversas formas de violência e criminalidade. As políticas adotadas pelas polícias civil e militar se mostram pouco eficazes no combate a essa situação (PONCIONI, 2005). As críticas acerca da segurança pública são muitas, principalmente no que se refere à atuação do policial. Nessa direção, este trabalho se propõe a olhar para os aspectos que permeiam a saúde mental de policiais militares, homens que arriscam suas vidas para a proteção do cidadão em geral. Assim sendo, trata-se de uma temática de interesse acadêmico e social. Independente, ou não, de significar a verdade absoluta dos fatos, revela uma versão para os acontecimentos vivenciados por esses profissionais.

São considerados servidores militares os indivíduos que, em caráter permanente ou transitório, prestam serviços militares no plano da administração da União e dos Estados. Sendo assim, pode-se dizer que os policiais militares se referem aos profissionais que desempenham atividade no âmbito federal ou no estadual, recebendo por este serviço um subsídio. Para um bom exercício profissional, o militar deve saber lidar 
com o conjunto de tarefas a ele conferidas e não se abster de cumprir suas obrigações, mesmo que isso implique em algum dilema ideológico pessoal (GASPARINI, 2001; JESUS, 2001).

Mirabete (1998) e Guimarães (1999) apontam que a atividade militar não se resume ao serviço diário, a função implica em constante estado de alerta, mesmo quando o profissional está em momento de descanso. A profissão do policial requer que este indivíduo atue no confronto contra a conduta irregular ou criminosa da sociedade, defendendo cidadãos.

Silva e Leite (2007) chamam atenção para o fato de que, muitas vezes, os policiais são tidos pela população como violentos e imprevisíveis. Muitos cidadãos, sobretudo aqueles que vivem em áreas periféricas e violentas ou em contextos de favelas, não confiam no policial, pois julgam que os mesmos apresentam conduta discriminatória e, por vezes, duvidosa diante da comunidade. Desse modo, a figura do policial fica prejudicada, especialmente quando se considera que diversos policiais demonstram uma conduta profissional respaldada na ética e na responsabilidade de seus atos.

Observa-se que o policial militar deve distinguir o bem do mal, não podendo desprezar o elemento ético de sua conduta. Ele terá que decidir entre o legal e o ilegal, o justo e o injusto e também entre o honesto e o desonesto (ROSA, 2001; VALLA, 2000). Nesta perspectiva, o estudo de Guimarães, Torres e Faria (2005) evidenciou que os policiais militares, quando questionados sobre ações extrajudiciais, isto é, inapropriadas, a maior parte dos respondentes repudiou tais ações. Para os participantes, os valores democráticos devem permanecer, visto que estes são respaldados no respeito aos direitos humanos. Contudo, nem sempre a prática policial permite essa clareza na atuação, e essa constante pressão gera no profissional estados de incertezas e angústias. 
Os policiais têm pouca mobilidade para tomar decisões, já que as atividades sempre estão condicionadas ao cumprimento estrito da ordem de um superior. Ao averiguarem as representações sociais de policiais civis sobre a profissionalização, Brito e Souza (2004) evidenciaram que esses policiais consideram que, muitas vezes, há subserviência da polícia quanto ao atendimento dos interesses de grupos políticos dominantes.

Os policiais sofrem influências de vários fatores negativos que geram estresse extremo. O cansaço físico e a falta de equilíbrio emocional podem levar esses profissionais a assumirem atitudes irracionais durantes crises e situações caóticas. Assim, tais atitudes podem levar à falta de eficácia no desempenho do exercício profissional, expondo os policiais e a população em geral a perigos em potencial. Valla (2002) afirma que a profissão militar caracteriza-se por exigir do indivíduo inúmeros sacrifícios, inclusive o da própria vida, em prol da vida do outro. A morte é uma realidade na vida deste profissional visto que o mesmo tem que saber lidar com a morte das vítimas, dos criminosos, dos próprios companheiros de trabalho e também com a ideia de que sua própria vida corre perigo.

$\mathrm{Na}$ atividade policial, por se tratar de uma atuação profissional tão perigosa, há que se considerar que um ambiente familiar saudável e horas de repouso e lazer poderiam contribuir para um melhor equilíbrio mental na realização das muitas tarefas profissionais. Contudo, Assis (1999) e Minayo, Souza e Constantino (2007) discutem que muitos policiais militares prestam serviços em seus horários de folga para complementar a renda. A segurança particular é exercida periodicamente, quase sempre aos finais de semana ou em dias alternados com os trabalhos da corporação. Com isso o policial fica exposto a um maior desgaste físico e mental.

Para Souza e Minayo (2005), muitos são os casos de agravos à saúde física e mental dos policiais militares. No geral, os policiais são vítimas de acidentes e violências que levam à morte prematura. Um estudo feito 
com policiais civis, realizado por Souza, Franco, Meireles, Ferreira e Franco (2007), evidenciou que esses policiais estão expostos a estresse no seu cotidiano laboral. Essa realidade gera sofrimento psíquico, consequentemente reduz a eficácia da atuação profissional. Este fato não é diferente quando se considera o policial militar, conforme aponta Porto (2004). No Brasil, ainda há poucas pesquisas desenvolvidas em âmbito nacional com os muitos batalhões da Polícia Militar, que permitam conhecer como o policial militar se percebe e avalia sua saúde mental.

O sofrimento humano pode estar associado ao processo laboral e, para tanto, se faz necessário compreender suas causas a fim de modificálo e reorganizar contingências mais favoráveis ao processo de trabalho. O estresse, nesse contexto, é resultante da interação das características do indivíduo e das influências sofridas por ele por meio do contexto ambiental, isto é, trata-se da relação entre os meios internos e externos, juntamente com a percepção do indivíduo acerca de sua própria capacidade de resposta e enfrentamento (DEJOURS, 1992; LIPP, 1996).

O estresse pode ser entendido como o desequilíbrio entre as demandas do trabalho e a capacidade de resposta dos trabalhadores. Fatores estressantes como um ambiente de trabalho perigoso, baixo controle sobre o processo de trabalho (cumprimento de ordens), frequente contato com o público (atendimento da comunidade geral), longas jornadas de trabalho (em razão da escala), recursos insuficientes, insatisfação com a atividade e a remuneração, dificuldade de ascensão profissional, além da exposição ao sofrimento alheio e a problemas familiares, estariam relacionados ao sofrimento ou distúrbios psíquicos e, no caso dos policiais, todos esses fatores estão presentes (LIPP; PEREIRA; SADIR, 2005; MINAYO; SOUZA, 2003; ROMANO, 1996).

O estresse é uma reação emocional na qual o corpo produz substâncias que terão um efeito no organismo, visando protegê-lo de alguma 
situação que cause medo, confusão ou excitação. No estresse aparecem certas reações que são observáveis: taquicardias, tensão muscular, mãos frias e suadas, sensação de nó no estômago, ombros ligeiramente levantados, e estado de alerta permanente (BACCARO, 1990; MARGIS; PICON; COSNER; SILVEIRA, 2003).

Um dos agravantes do estresse no trabalho do policial pode estar associado à limitação que a sociedade submete pessoas quanto às manifestações de suas angústias, frustrações e emoções. Esse fato fica ainda mais grave no caso do policial, pois, se não há espaço para que tais manifestações sejam reveladas e trabalhadas, então, possivelmente, esses sintomas podem ser prejudiciais diante de uma situação que envolve risco.

O policial lida com riscos reais e imaginários, na profissão. Assim, o sofrimento e o estresse apresentam agravamentos e mesmo quando imaginários, podem desencadear respostas de alerta e até mesmo levá-lo à morte. Benevides-Pereira (2002) admite que os profissionais que trabaIham em funções diretamente na assistência dos outros, estão suscetíveis ao estresse. Os sintomas podem ser definidos da seguinte forma: fadiga constante e progressiva, dores musculares, distúrbios do sono, perturbações gastrintestinais. Podem ocorrer também falta de atenção e concentração, alterações da memória, baixa auto-estima, labilidade emocional, impaciência e dificuldades comportamentais associadas à negligência ou escrúpulo excessivo, à irritabilidade e aumento da agressividade, à dificuldade de relaxar, ao alto consumo de substâncias, ao risco de suicídio e aos sintomas defensivos que tangem tendência ao isolamento, sentimento de onipotência, perda de interesse pelo trabalho, ironia e cinismo.

Assim sendo, por se considerar a profissão do policial militar algo de suma importância para a sociedade e com base nas considerações trazidas, aventa-se a hipótese de que os policiais em diferentes atuações profissionais podem ser acometidos de cansaço físico e emocional e pos- 
sivelmente terem a percepção de que estão estressados. Desse modo, levantar a percepção que policiais militares da Força tática e de Rua têm acerca dos aspectos que permeiam sua própria saúde mental, foi o objetivo deste estudo.

\section{Método}

Este trabalho é um estudo exploratório e de levantamento de dados, com característica da pesquisa descritiva (BAPTISTA; CAMPOS, 2007). A opção por essa abordagem metodológica se deve ao fato de que pouco se sabe sobre a percepção que esses policiais têm de sua própria saúde mental, portanto, torna-se relevante levantar e explorar essa informação, sobretudo no que se refere ao desenvolvimento de futuras pesquisas sobre o tema. Aventou-se a hipótese de que não é possível exercer uma função de cuidador, pois o policial também exerce esse papel, se, na verdade, esse profissional precisa de cuidados e assistência psicológica. Desse modo, na sequência, serão apresentados a caracterização dos participantes, os materiais utilizados e os procedimentos de coleta de dados.

Participantes

Participaram 24 policiais de dois Batalhões da Polícia Militar do Estado de São Paulo. O primeiro Batalhão contava com aproximadamente 70 policiais distribuídos entre policiais da Força Tática, e policiais de Rua. Apenas 13 (54,1\%) policiais de rua consentiram na participação nesse Batalhão e não foi possível conseguir a colaboração dos policiais da Força Tática. No segundo Batalhão pesquisado, de um total de aproximadamente 280 policiais da Força Tática, obteve-se a participação de 11 $(45,9 \%)$. Tendo em vista as dificuldades encontradas para que os policiais colaborassem, o universo total ficou reduzido a 24 policiais. 
A média de idade foi de 33 anos e 5 meses, a idade mínima foi de 18 anos e a máxima, de 50 . O gênero masculino representou 79,2\% $(n=19)$ da amostra, e o feminino $20,8 \%(n=5)$. No que se refere à escolaridade, observou-se que a maior parte $(54,2 \%, n=13)$ apresentava o ensino médio completo, a outra parte $(41,7 \%, n=10)$ tinha o ensino superior completo, e a menor parte $(4,2 \% n=1)$ possuía o ensino fundamental completo.

Instrumentos

Uma escala foi utilizada, desenvolvida pelas autoras deste estudo, contendo 30 questões abordando assuntos relativos ao cansaço físico e emocional e à percepção do estresse. As questões estavam dispostas em escala likert de 3 pontos, na qual levantava-se a frequência de ocorrência do comportamento, isto é, sempre, às vezes, nunca. Em todos os casos, os participantes assinalaram com um $\mathrm{x}$ apenas uma alternativa de resposta.

\section{Procedimento}

A coleta foi realizada individualmente em horário previamente estabelecido na instituição militar, com os policiais que assinaram o termo de consentimento livre e esclarecido. Inicialmente a aplicadora esclareceu os objetivos do estudo, assegurou a confidenciabilidade dos dados individuais do participante e tirou eventuais dúvidas acerca da pesquisa e na sequência, a aplicação era iniciada. Toda aplicação dependeu da disponibilidade de horário de cada participante devido à rotatividade de turnos dos mesmos e teve duração aproximada de 20 minutos. Cabe esclarecer que este projeto foi aprovado pelo Comitê de Ética em Pesquisa da Universidade à qual esta pesquisa está vinculada, portanto, todos os procedimentos éticos foram seguidos e estão respaldados na Resolução 196/96 do Conselho Nacional de Saúde. 


\section{Resultados}

Os dados foram organizados em planilha excel e submetidos à estatística descritiva, visando atender o objetivo deste estudo. Na sequência, serão apresentadas as respostas dadas pelos policiais, tratando-se de um texto nesse primeiro momento descritivo, com dados percentuais detaIhados, mas que posteriormente serão discutidos e avaliados analiticamente. Inicialmente buscou-se levantar se os policiais exerciam mais alguma profissão (bico). Desse modo, 8,3\% $(n=2)$ responderam que sempre faziam bico, $12,5 \%(n=3)$ responderam às vezes e $79,2 \%(n=19)$ assinalaram a opção nunca. Para os policiais da Força Tática, os resultados para as alternativas, sempre e às vezes, foram, respectivamente, 9,1\% $(n=1) \mathrm{e}$ para nunca, $81,8 \%(n=9)$. No caso dos policiais de Rua, 7,7\% $(n=1)$ responderam à opção sempre, $15,4 \%(n=2)$ às vezes e $76,9 \%(n=10)$ nunca.

A questão seguinte verificou se os participantes sentiam-se pressionados por seus superiores. De acordo com os dados, foi possível identificar que $8,3 \%(n=2)$ consideraram que sempre eram pressionados, $58,3 \%(n=14)$ responderam "às vezes" e 33,3\% $(n=8)$ assinalaram nunca. No que diz respeito aos policiais da Força Tática, constatou-se que $72,7 \%(n=8)$ responderam que às vezes se sentiam pressionados e $27,3 \%(n=3)$ responderam "nunca". Para os policiais de Rua, 15,4\% $(n=2)$ responderam "sempre", 46,1\% $(n=6)$ responderam "às vezes" e 38,5\% $(n=5)$ responderam "nunca".

O estresse percebido pelos policiais e a percepção acerca do estresse no exercício profissional foram averiguados. A Tabela 1 apresenta os dados relativos ao policial sentir-se estressado atualmente e considerar seu trabalho estressante. 
Tabela 1. Frequência e porcentagem das respostas que versaram sobre sentir-se estressado atualmente e considerar seu trabalho estressante.

\begin{tabular}{|c|c|c|c|c|}
\hline \multirow{1}{*}{ Questões } & Grupo & $\begin{array}{c}\text { Sempre } \\
\mathrm{F} \mathrm{e} \%\end{array}$ & $\begin{array}{c}\text { Às Vezes } \\
\mathrm{F} \mathrm{e} \%\end{array}$ & $\begin{array}{c}\text { Nunca } \\
\mathrm{F} \mathrm{e} \%\end{array}$ \\
\hline \multirow{4}{*}{$\begin{array}{l}\text { Você se sente } \\
\text { estressado? }\end{array}$} & Dados Gerais & 6 & 16 & 2 \\
& Força Tática & 25 & 66,7 & 8,3 \\
\cline { 2 - 5 } & Policiais de Rua & 4 & 8 & 1 \\
& & 30,8 & 72,7 & 9,1 \\
\hline \multirow{2}{*}{$\begin{array}{c}\text { Você considera } \\
\text { seu trabalho } \\
\text { estressante? }\end{array}$} & Dados Gerais & 4 & 61,5 & 1 \\
& & 16,7 & 19 & 7,7 \\
\cline { 2 - 5 } & Força Tática & 1 & 79,1 & 1 \\
& & 9,1 & 9 & 1 \\
\cline { 2 - 5 } & Policiais de Rua & 3 & 81,8 & 9,1 \\
\hline & & 23,1 & 10 & \\
\hline
\end{tabular}

Em uma questão verificou-se sobre o policial sentir-se fisicamente cansado após o dia de trabalho. Assim, pôde-se perceber que 41,7\% $(n=10)$ dos colaboradores responderam que sempre se sentiam cansados após o término do dia de trabalho, $50 \%(n=12)$ assinalaram às vezes e $8,3 \%(n=2)$ nunca. No que se refere às respostas dos policiais da Força Tática, observou-se que 36,4\% $(n=4)$ responderam "sempre", $54,5 \%$ $(n=6)$ responderam "às vezes" e 9,1\% $(n=1)$ responderam "nunca". Para os policiais de Rua, tanto na resposta sempre, quanto na alternativa, às vezes, obteve-se $46,1 \%(n=6)$ e $7,7 \%(n=1)$ responderam que nunca se sentiam cansado após o dia de trabalho.

Quanto ao sujeito sentir-se emocionalmente cansado após o dia de trabalho, esse dado foi levantado: $33,3 \%(n=8)$ consideraram sempre se sentirem emocionalmente cansados; $50 \%(n=12)$ disseram "às vezes" $\mathrm{e}$ $16,7 \%(n=4)$ nunca. Nas respostas dadas pelos policiais da Força Tática evidenciou-se que $27,3 \%(n=3)$ responderam sempre; $54,5 \%(n=6)$ responderam às vezes e $18,2 \%(n=2)$ afirmaram que nunca se sentiam 
emocionalmente cansados após o dia de trabalho. Para os policiais de rua, a resposta sempre contemplou $38,5 \%(n=5)$, às vezes, $46,1 \%(n=6)$ e nunca $15,4 \%(n=2)$.

Observou-se o fato de os policiais terem tido lapsos de memória. A resposta sempre foi respondida por 8 (33,3\%) policiais, "às vezes" por 12 (50\%) e "nunca" por 4 (16,7\%). Segundo a análise dos Policiais da Força Tática e de Rua, observou-se que no primeiro grupo 9,1\% $(n=1)$ apontaram a resposta "sempre", 63,6\% $(n=7)$ indicaram "às vezes" e $27,3 \%(n=3)$ apontaram "nunca" como alternativa de escolha. No segundo grupo, constatouse que $23 \%(n=3)$ escolheram sempre; $38,5 \%(n=5)$ escolheram "às vezes" e por fim, 38,5\% ( $n=5)$ optaram pela alternativa "nunca".

Quanto à falta de concentração dos policiais, a maior parte $(62,5 \%$, $n=15$ ) disse que tinha episódios de falta de concentração, a outra parte $(33,3 \%, n=8)$ disse que "às vezes" e a menor parcela $(4,2 \%, n=1)$ respondeu "nunca". Com isso, percebeu-se que nos policiais de Força Tática, 9,1\% ( $n=1)$ afirmaram ter apresentado falta de concentração; 72,7\% $(n=8)$ afirmaram que às vezes tinham falta de concentração e que $18,2 \%$ $(n=2)$ nunca tiveram falta de concentração. Já para os policiais de Rua, a questão às vezes correspondeu a $61,5 \%(n=8)$ e $38,5 \%(n=5)$ representam os que escolheram como resposta a alternativa "nunca".

No que se refere aos episódios de insônia e sonolência durante o dia de trabalho, esses dados foram observados. Na Tabela 2 podem ser vistos os dados de frequência e porcentagem das respostas. 
Tabela 2. Distribuição das frequências e porcentagens das respostas quanto aos policiais terem tido insônia e apresentarem sonolência durante o dia de trabalho.

\begin{tabular}{|c|c|c|c|c|}
\hline Questões & Grupo & $\begin{array}{c}\text { Sempre } \\
\mathrm{F} \mathrm{e} \%\end{array}$ & $\begin{array}{c}\text { Às Vezes } \\
\mathrm{F} \mathrm{e} \%\end{array}$ & $\begin{array}{c}\text { Nunca } \\
\mathrm{F} \mathrm{e} \%\end{array}$ \\
\hline \multirow{4}{*}{$\begin{array}{l}\text { Você tem sofrido } \\
\text { com a insônia? }\end{array}$} & Dados Gerais & 1 & 10 & 13 \\
& Força Tática & 4,2 & 41,7 & 54,1 \\
\cline { 2 - 5 } & Policiais de Rua & 1 & 3 & 8 \\
& 7,6 & 27,3 & 72,7 \\
\hline \multirow{2}{*}{$\begin{array}{c}\text { Você tem sofrido } \\
\text { sonolência } \\
\text { durante o } \\
\text { trabalho? }\end{array}$} & Dados Gerais & 1 & 7 & 5 \\
\cline { 2 - 5 } & Força Tática & 4,2 & 19 & 38,5 \\
\cline { 2 - 5 } & Policiais de Rua & 1 & 79,1 & 1 \\
& & 7,7 & 5 & 6,2 \\
\hline
\end{tabular}

Foi analisado se os participantes costumavam ter pesadelos. Pôde-se perceber que $8,3 \%(n=2)$ sempre tinham pesadelos, $41,7 \%(n=10)$ às vezes tinham e $50 \%(n=12)$ nunca tinham. Dessa forma, verificou-se que a maior parte $(63,6 \%, n=7)$ dos policiais da Força Tática afirmou nunca ter pesadelos, a outra parte $(36,4 \% n=4)$ afirmou que às vezes tinha pesadelos. Para os policiais de Rua, as afirmações sempre e às vezes receberam ambas o percentual de $46,1 \%(n=6)$ e a menor parte $(7,7 \%, n=1)$ afirmou que nunca tinha pesadelo.

Levantou-se em uma questão, se ultimamente as ocorrências deixavam os policiais irritados. Assim sendo, 75\% $(n=18)$ dos policiais disseram que às vezes as ocorrências os deixavam irritados, outra parte (20,8\%, $n=5$ ) disse que as ocorrências nunca os deixavam irritados e a menor parte $(4,2 \%, n=1)$ optou pela alternativa "sempre". Para os policiais da Força Tática, o total de "às vezes" correspondeu a $81,8 \%(n=9)$ e o de nunca correspondeu a $18,2 \%(n=2)$. Enquanto que para os policiais de rua, $7,7 \%(n=1)$ correspondeu ao total de "sempre", 69,2\% $(n=9)$ de "às vezes" e $23,1 \%(n=3)$ de "nunca". 
Avaliou-se, em uma questão, se os policiais se percebiam agressivos. Dessa forma, 4,2\% $(n=1)$ sempre se percebiam, para $62,5 \%(n=15)$ "às vezes" isso acontecia e 33,3\% $(n=8)$ afirmaram "nunca"; 72,7\% $(n=8)$ dos policiais da Força Tática, "às vezes", se percebiam agressivos e, para $27,3 \%(n=3)$, isso "nunca aconteceu". No caso dos policiais de Rua, 7,7\% $(n=1)$ sempre se percebiam, $46,1 \%(n=6)$ às vezes se percebiam e $46,1 \%$ $(n=6)$ nunca se percebiam.

No que se refere aos fatos dos policiais se sentirem impulsivos, já terem tomado alguma atitude inconsciente na carreira e já terem agido impulsivamente em alguma ocorrência, os dados podem ser observados na Tabela 3 e, é possível também observar os dados da frequência e porcentagem das respostas.

Tabela 3. Dados da frequência e porcentagens das respostas quanto à percepção e tomada de atitudes por impulsividade.

\begin{tabular}{|c|c|c|c|c|}
\hline Questões & Grupo & $\begin{array}{c}\text { Sempre } \\
\mathrm{Fe} \%\end{array}$ & $\begin{array}{c}\text { Às Vezes } \\
\text { F e \% }\end{array}$ & $\begin{array}{c}\text { Nunca } \\
\mathrm{Fe} \%\end{array}$ \\
\hline \multirow{3}{*}{$\begin{array}{l}\text { Você tem se per- } \\
\text { cebido impulsivo } \\
\text { nas decisões? }\end{array}$} & Dados Gerais & $\begin{array}{c}1 \\
4,2\end{array}$ & $\begin{array}{c}10 \\
41,7\end{array}$ & $\begin{array}{c}13 \\
54,1\end{array}$ \\
\hline & Força Tática & & $\begin{array}{c}3 \\
27,3\end{array}$ & $\begin{array}{c}8 \\
72,7\end{array}$ \\
\hline & Policiais de Rua & $\begin{array}{c}1 \\
7,6\end{array}$ & $\begin{array}{c}7 \\
53,8\end{array}$ & $\begin{array}{c}5 \\
38,5\end{array}$ \\
\hline \multirow{3}{*}{$\begin{array}{c}\text { Você já tomou } \\
\text { alguma atitude } \\
\text { inconseqüente } \\
\text { na carreira? }\end{array}$} & Dados Gerais & $\begin{array}{c}1 \\
4,2\end{array}$ & $\begin{array}{c}19 \\
79,1\end{array}$ & $\begin{array}{c}1 \\
4,2\end{array}$ \\
\hline & Força Tática & & $\begin{array}{c}5 \\
45,5\end{array}$ & $\begin{array}{c}6 \\
54,5\end{array}$ \\
\hline & Policiais de Rua & $\begin{array}{c}1 \\
7,7\end{array}$ & $\begin{array}{c}6 \\
46,1\end{array}$ & $\begin{array}{c}6 \\
46,1\end{array}$ \\
\hline \multirow{3}{*}{$\begin{array}{l}\text { Você já agiu } \\
\text { impulsivamente } \\
\text { em alguma } \\
\text { ocorrência? }\end{array}$} & Dados Gerais & & $\begin{array}{c}8 \\
33,3\end{array}$ & $\begin{array}{c}16 \\
66,7\end{array}$ \\
\hline & Força Tática & & $\begin{array}{c}6 \\
54,5\end{array}$ & $\begin{array}{c}5 \\
45,5\end{array}$ \\
\hline & Policiais de Rua & & $\begin{array}{c}2 \\
15,4\end{array}$ & $\begin{array}{c}11 \\
84,6\end{array}$ \\
\hline
\end{tabular}


A questão subsequente versou se os sujeitos já haviam sentido arrependimento em razão de seu ato em alguma ocorrência. Sendo assim, analisou-se que $37,5 \%(n=9)$ às vezes se arrependeram de algum ato cometido nas ocorrências e $62,5 \%(n=15)$ nunca haviam se arrependido. No caso dos policiais da Força Tática, 36,4\% $(n=4)$ às vezes sentiram arrependimento e $63,6 \%(n=7)$ nunca sentiram e, no outro grupo, $38,5 \%(n=5)$ relataram que, às vezes, isso ocorria e $61,5 \%(n=8)$ responderam à opção "nunca".

Levantou-se em uma questão se os grupos analisados já haviam pensado em pedir afastamento. Sendo assim, verificou-se que $70,8 \%(n=17)$ "nunca" pensaram em pedir afastamento, $25 \%(n=6)$ "às vezes" pensaram em pedir afastamento e 4,2\% $(n=1)$ "sempre" pensaram em pedir afastamento. Dessa forma, analisou-se que o percentual total das respostas dadas pelos policiais da Força Tática correspondeu a 18,2\% $(n=2)$ para "às vezes e $81,8 \%(n=9)$ para "nunca". O percentual "sempre" para os policiais de Rua foi de 7,7\% ( $n=1)$, "às vezes" 30,8\% ( $n=4)$ e "nunca" 61,5\% $(n=8)$.

Averiguou-se o fato de os policiais já terem pensado em suicídio. Com isso percebeu-se que $20,8 \%(n=5)$, às vezes, pensaram em se suicidar e 79,2\% ( $n=19)$ "nunca" pensaram. Ao se considerar os grupos, $27,3 \%(n=3)$ dos policias da Força Tática "às vezes" pensaram em se suicidar e o restante $(72,7 \%, n=8)$ "não". Quanto aos policiais de Rua, $15,4 \%(n=2)$ também "às vezes" pensaram em cometer suicídio e os demais $(84,6 \% ; n=11)$ "não".

No que se refere ao relacionamento familiar, questionou-se o quanto tal relacionamento afetava o desempenho profissional dos policiais. Com isso, verificou-se que $37,5 \%(n=9)$ afirmaram que o relacionamento familiar "às vezes" comprometia o desempenho profissional e $62,5 \%$ $(n=15)$ afirmaram que isso "nunca" acontecia. De acordo com os dados levantados para os policiais da Força Tática, verificou-se que 36,7\% $(n=4)$ responderam que "às vezes" o relacionamento familiar afetava o 
desempenho profissional e 63,3\% $(n=7)$ responderam a opção "nunca". No caso dos policiais de Rua, percebeu-se um percentual de resposta de $38,5 \%(n=5)$ para "às vezes" e $61,5 \%(n=8)$ para "nunca".

Uma questão remeteu ao fato de os problemas do trabalho afetarem a rotina familiar. Com isso, para $45,8 \%(n=11)$ a rotina familiar às vezes era "afetada" e para $54,2 \%(n=13)$ a rotina familiar "nunca foi afetada" pelos problemas decorrentes do trabalho. Percebeu-se que a rotina familiar dos policiais da Força Tática "às vezes" $(45,5 \%, n=5)$ era afetada por problemas de trabalho e $54,5 \%(n=6)$ consideraram que isso nunca acontecia. O percentual de "às vezes" para os policiais de Rua foi de $46,1 \%$ $(n=6)$ e de "nunca" foi de $53,8 \%(n=7)$.

Uma questão investigou se os policiais gostavam de sua profissão. A Tabela 4 mostra as porcentagens dos grupos quanto a gostar de sua profissão e estar feliz com o cargo exercido.

Tabela 4. Frequência e porcentagens de respostas relativas à gostar da profissão e estar feliz com o cargo exercido.

\begin{tabular}{|c|c|c|c|c|}
\hline Questões & Grupo & $\begin{array}{c}\text { Sempre } \\
\mathrm{F} \mathrm{e} \%\end{array}$ & $\begin{array}{c}\text { Às Vezes } \\
\mathrm{F} \mathrm{e} \%\end{array}$ & $\begin{array}{c}\text { Nunca } \\
\mathrm{F} \mathrm{e} \%\end{array}$ \\
\hline \multirow{4}{*}{$\begin{array}{l}\text { Você gosta de } \\
\text { sua profissão? }\end{array}$} & Dados Gerais & 21 & 10 & 13 \\
& Força Tática & 11 & 41,7 & 54,1 \\
\cline { 2 - 5 } & Policiais de Rua & 100 & 3 & 8 \\
& & 84,6 & 72,3 & 72,7 \\
\hline \multirow{2}{*}{$\begin{array}{c}\text { Você está } \\
\text { feliz com o cargo } \\
\text { exercido? }\end{array}$} & Dados Gerais & 15 & 53,8 & 5 \\
& & 62,5 & 7 & 38,5 \\
\cline { 2 - 5 } & Força Tática & 9 & 29,2 & 2 \\
\cline { 2 - 5 } & Policiais de Rua & 7 & 2 & 8,3 \\
\hline & & 53,8 & 18,2 & \\
\hline
\end{tabular}


Por fim, averiguou-se o fato de os participantes se sentirem realizados como policiais. Com isso, $66,7 \%(n=16)$ responderam que "sempre" se sentiam realizados, $25 \%(n=6)$ responderam que "às vezes" se sentiam realizados e $8,3 \%(n=2)$ responderam à opção "nunca". Constatou-se que para $81,8 \%(n=9)$ dos policiais da Força Tática, o sentimento de realização "sempre" era percebido e para $18,2 \%(n=2)$ isso acontecia "às vezes". Entre os policiais de Rua, 46,1\% $(n=6)$ "sempre" se sentiam realizados, $38,5 \%(n=5)$ "às vezes" se sentiam e $15,4 \%(n=2)$ afirmaram "nunca" se sentir desse modo.

\section{Discussão}

Cabe esclarecer que as respostas dadas pelos participantes não correspondem necessariamente à realidade. Quando se trata de instrumento de cunho mais subjetivo (questionário especialmente desenvolvido para este estudo), que conta com a 'sinceridade' do avaliando, temos que lidar com a possibilidade de que as respostas podem ter apresentado algum viés. Contudo, também devemos olhar para esse dado como representativo do relato de como esses policiais se sentem e como se percebem em sua atuação profissional. Assim, o que se pode dizer é que esses dados, embora dignos de consideração, devem ser vistos com cautela.

No que refere-se à realização de atividades profissionais exercidas fora do horário de trabalho, apenas 20,8\% responderam que "sempre" ou "às vezes" essa era uma prática comum. Embora esse percentual seja pequeno, houve maior incidência de policiais que realizavam bicos no grupo dos policiais de Rua, talvez pela remuneração menor. Os dados obtidos neste estudo não corroboram as considerações de Assis (1999) e Minhayo e cols. (2007), que indicam que o bico, embora seja uma atividade não permitida, é algo realizado com frequência por muitos policiais. Ao 
que parece, neste estudo, poucos foram aqueles que revelaram fazer bico, e esse fato é realmente curioso, uma vez que o bico poderia melhorar a renda desse policial. Seria ingênuo não citar que o risco que o policial corre diariamente no exercício de sua tarefa deveria ser passível de maior recompensa financeira, mas a realidade não é essa, o que leva esse profissional a recorrer, em muitos casos, ao bico. Levanta-se também a hipótese de que é possível que alguns participantes não tenham revelado que realizam bico por não confiarem que os seus dados pessoais não seriam revelados aos seus superiores. Também parece que esse resultado denuncia a falta de investimentos públicos quanto à melhora dos salários desses profissionais, remetendo-os a um contínuo ritmo de trabalho na corporação e fora dela. Essa carga dobrada, possivelmente aumenta o cansaço físico e o desgaste emocional e depõe de forma negativa para a saúde mental do policial. Majoritariamente a corporação militar anseia por melhores condições de trabalho, contudo ao se submeter aos bicos, esses profissionais se expõem ao risco (condições de trabalho e segurança precárias).

Atualmente a polícia militar está mais humanizada, contudo ainda está longe de se apresentar um funcionamento mais democrático para os policiais que atuam nesse contexto. Na presente pesquisa dos 24 respondentes, 16 relataram que sempre ou, às vezes, se sentem pressionados por seus superiores. A maior incidência de policiais estava no grupo da Força Tática. Hipotetiza-se isso ter acontecido, pois os policiais da Força Tática constituem um grupo de elite que deve atuar em situações de extrema pressão, o que explicaria a cobrança dos superiores. A busca pela total eficácia no cumprimento do dever remete à consideração de que a pressão constante e a falta de abertura para questionar ordens inapropriadas poderiam constituir fatores que, em longo prazo, poderiam gerar desconforto e angústias no ambiente de trabalho, o que prejudicaria o bom desempenho profissional e a saúde mental do policial. Há que se pensar 
que existem barreiras nos relacionamentos interpessoais entre os policiais, especialmente aqueles que exercem funções de liderança e os que são liderados. Na corporação não há espaço para muitas reflexões e, ao que parece, possivelmente será difícil transpor dificuldades que permeiam aspectos como emoção, empatia, entre outros. Nessa direção, fomenta-se a necessidade de um trabalho psicológico, de modo que este possa representar um canal aberto de comunicação e melhora nas relações de trabaIho. Também pode-se levantar a hipótese de que essas dificuldades são decorrentes de um histórico do militarismo no qual se privilegia a falta de abertura para o diálogo e para a reflexão acerca dos sentimentos e emoções. Com isso, a corporação como um todo 'se solidifica', mas somente por fora, pois, por dentro, essa corporação é feita de homens e mulheres que sentem e, por conseguinte, estão sujeitos ao sofrimento psicológico.

No que tange ao estresse percebido e à percepção do estresse no exercício profissional, os dados revelaram que a maior parte $(91,7 \%)$ dos policiais se sente estressada sempre ou às vezes. No grupo dos policiais de Rua está o maior percentual (92,3\%) de policiais que, sempre, ou às vezes se sente estressado. Quanto a considerar o trabalho estressante, a maioria $(95,8 \%)$ sempre ou, às vezes, considera o maior percentual $(100 \%)$ de policiais que o fazem está no grupo dos policiais de Rua. Romano (1996) aponta que o ambiente de trabalho do policial é perigoso e apresenta grande exposição e risco iminente de morte. Tanto os policiais da Força Tática quanto os de Rua responderam que se percebem estressados e não causa estranheza o fato de o grupo de Rua ser mais susceptível a essa percepção, pois esse grupo é chamado para atender todos os tipos de ocorrências, diferente do outro grupo. Possivelmente, a cada ocorrência, há uma chance real de risco de morte e, quando se considera a cidade de São Paulo, região metropolitana, a probabilidade de acontecer uma tragédia é muito grande. De um lado, o policial pode ser vitimado e, de 
outro, ele pode presenciar durante um único dia muitos casos de cidadãos vitimados por acidentes ou episódios de violência. O fato é que o policial de Rua está, possivelmente, em maior contato com a dor e com a morte. Assim, mais uma vez fica evidente a necessidade de projetos de bem-estar psicológico direcionados ao policial militar, pois situações muito estressantes podem, em longo prazo, gerar efeitos colaterais severos como o desenvolvimento de patologias, ou na falta de controle acerca do comportamento agressivo, esses fatores constituem risco direto à população.

A maioria dos policiais sempre, ou às vezes, se percebe com cansaço físico $(91,7 \%)$ e com cansaço emocional $(83,3 \%)$ após o dia de trabalho. O maior percentual de respondentes no sempre e, às vezes, tanto no cansaço físico $(92,2 \%)$ quanto no cansaço emocional $(84,6 \%)$, estava entre os policiais de Rua. O cansaço físico e emocional pode acarretar sempre, ou às vezes, episódios de lapsos de memória (88,3\%) e falta de concentração (95,8\%). Nos dois casos, a incidência maior de sempre, às vezes estava no grupo da Força Tática (72,7\% e 81,8\%, respectivamente). Autores como Minayo e cols. (2007) não descartam falta de equilíbrio entre as demandas de trabalho às quais os policiais são submetidos, bem como as condições emocionais que o mesmo apresenta. Trata-se de uma atuação com muitos fatores estressantes, que exigem muito da capacidade de resposta do mesmo, sem a devida e necessária assistência emocional mais atenta à prevenção.

A insônia e a sonolência durante o dia de trabalho também foram levantados. No caso da insônia, apenas uma parte $(45,9 \%)$ relatou sofrer com esse quadro, sendo que o maior percentual $(61,4 \%)$ se concentrou no grupo da Força Tática. A metade (50\%) da amostra relatou sofrer de sonolência durante o dia de trabalho. Mais uma vez, a metade (50\%) afirmou que sempre, ou às vezes, costumava ter pesadelos; esse fato foi mais marcante no grupo dos policiais de Rua, sendo que 92,2\% dos policiais sempre ou às vezes tinham pesadelos. Alterações e distúrbios no sono são 
apontados por Benevides-Pereira (2002) como sintomas que evidenciam sinais de estresse laboral, sobretudo em atuações que envolvem assistência aos outros, como é o caso dos policiais militares. É também compreensível que a incidência de pesadelos tenha sido maior entre os policiais de Rua, pois são eles que atendem todas as ocorrências e conforme já mencionado, durante o dia, esses profissionais vivenciam muitas situações com desfechos trágicos.

Sob esse aspecto, é possível entender por que 79,2\% dos policiais se percebiam irritados diante de uma ocorrência e, curiosamente, o maior percentual $(81,8 \%)$ de respondentes estava na Força Tática e não, entre os policiais de Rua que, por sua vez, se perceberam mais cansados física e emocionalmente. Destarte, a autopercepção da agressividade indicou que a maior parte $(66,7 \%)$ sempre, ou às vezes, se percebia agressiva. Esse comportamento foi mais observado em policiais da Força Tática. A irritação e o comportamento agressivo, de acordo com Benevides-Pereira (2002), podem ser requisitos para comportamentos violentos futuros que, por sua vez, seriam desastrosos no âmbito da segurança pública. Sob esse aspecto, a mídia televisiva e impressa relata os muitos episódios nos quais policiais militares agem de forma agressiva e violenta, causando grande desconfiança à população. Portanto, mais uma vez fica evidente a necessidade de que um trabalho psicológico mais efetivo, de forma que os policiais possam manter sempre uma boa saúde mental, o que possivelmente resultaria em ações mais comedidas, sobretudo aquelas direcionadas aos civis. Um ponto positivo desse dado é o fato de os policiais terem relatado que se percebem agressivos. Talvez esse seja um primeiro passo para uma mudança comportamental.

Na Tabela 3, foi possível verificar que $75 \%$ dos policiais já se perceberam impulsivos nas decisões e o maior percentual de citações foi no grupo da Força Tática (90,9\%). Assim sendo, 33,3\% já tomou alguma atitude inconsequente na carreira e, novamente, o maior percentual 
(54,5\%) estava na Força Tática. Por fim, 41,7\% dos policiais relataram que já agiram impulsivamente em alguma ocorrência, e coerentemente com os dados, o grupo da Força Tática obteve o maior percentual $(45,5 \%)$. Embora os comportamentos associados à impulsividade tenham sido percebidos pelos policiais, apenas $37,5 \%$ se arrependeram de algum ato cometido em alguma ocorrência. Guimarães e cols. (2005) defendem que os policiais repudiam ações inapropriadas e concordam que as ações devem ser direcionadas com respeito aos direitos humanos. Argumenta-se, contudo, que a clareza na atuação e a ação com equilíbrio exige o entendimento de outros fatores que permeiam essa profissão como o cansaço físico e emocional, alterações no sono, o baixo salário, a falta de recursos, entre outros. Tais fatores certamente influenciarão negativamente a conduta, causando baixa tolerância e falta de controle. Mais uma vez, seria ingênuo não mencionar que muitos são os episódios nos quais a polícia excede-se na sua conduta contra civis. Assim, embora muitos policiais repudiem as ações inapropriadas, estas ainda acontecem com frequência.

Porto (2004) e Souza e cols. (2007) argumentam que o cotidiano da atividade policial pode gerar sofrimento psíquico em razão da contínua pressão pela qual esses profissionais passam. Com os dados obtidos na presente pesquisa, foi possível levantar que uma parte significativa $(29,2 \%)$ dos policiais já pensou em pedir afastamento. O maior percentual (38,5\%) estava entre os policiais de Rua. Esse dado corrobora a hipótese de que esses profissionais, possivelmente, estão mais expostos ao estresse contínuo, tendo em vista o atendimento das diversas ocorrências diárias. Ao considerar que o sofrimento psíquico, tal qual apontam Souza e cols. (2007) e Porto (2004), pode chegar a uma consequência extrema como é o caso do suicídio, na presente pesquisa constatou-se que 20,8\% da amostra já pensaram em se suicidar, sendo que o maior percentual estava entre os policiais da Força Tática. 
Com a perspectiva de averiguar, na percepção dos policiais, se o relacionamento familiar poderia interferir no desempenho profissional e vice-versa, esses dados foram levantados. Uma parte considerável da amostra $(37,5 \%)$ respondeu que o desempenho profissional era afetado pelo relacionamento familiar, sendo que o maior percentual $(38,5 \%)$ estava entre os policiais de Rua. O dado inverso mostrou que, para 45,8\% da amostra, a rotina familiar era afetada pelos problemas de trabalho e, novamente, o grupo mais afetado $(46,1 \%)$ foi o dos policias de Rua. Esses resultados indicam que a amostra pesquisada também sofre com problemas familiares e problemas de trabalho e ambos podem interferir no bom desempenho profissional, sobretudo quando aliados ao estresse, falta de recursos, baixa remuneração, exposição a riscos, entre outros (LIPP; PEREIRA; SADIR, 2005; MINAYO; SOUZA, 2003; ROMANO, 1996). Mais uma vez, vale ressaltar a importância de um atendimento psicológico mais focado a esses profissionais que se arriscam para proteger a população, bem como há que se pensar em dispensar melhores condições de trabaIho como novos e bons equipamentos de segurança e melhores salários.

Embora esses profissionais enfrentem muitos problemas, a maior parte $(87,5 \%)$ afirmou gostar de sua profissão e $91,7 \%$ sempre e, às vezes, se percebiam felizes com o cargo exercido. Em ambas as situações, o grupo da Força Tática obteve o maior percentual de satisfação. Ainda foi possível levantar que $91,7 \%$ sempre, ou às vezes, percebiam-se realizados como policiais e, mais uma vez, o grupo da Força Tática obteve o maior percentual em relação à satisfação profissional. Com esses dados, podese hipotetizar que tais profissionais, embora enfrentem muitos aspectos difíceis e negativos em suas atuações e corram riscos de vida, ainda assim conseguem abstrair alguma realização profissional. Sob esse aspecto, fomenta-se a questão de que ainda com tantas dificuldades, esse fato pode ser evidenciado. Presume-se que novos e maiores investimentos por par- 
te do poder público, quem sabe, poder-se-ia observar profissionais mais saudáveis do ponto de vista afetivo-emocional e, consequentemente, mais eficazes na realização de sua tão fundamental atividade profissional.

\section{À guisa de conclusão}

O presente estudo explorou e discutiu a percepção dos policiais militares acerca de sua própria saúde mental, refletindo sobre questões que permeavam a rotina de trabalho, as emoções, os sentimentos e os comportamentos em relação a essa atuação. Uma das maiores dificuldades encontradas em todo o processo de execução foi conseguir quebrar as barreiras e as resistências dos colaboradores, mostrando aos mesmos que toda ou qualquer informação não seria repassada aos seus superiores, pois esta pesquisa estava respaldada pela Resolução 196/96 do Conselho Nacional de Saúde e que, portanto, os dados individuais seriam preservados. Outro fator importante foi desmistificar a noção dos colaboradores que aceitassem participar da pesquisa de que não seriam classificados de forma pejorativa, isto é, como 'loucos'. Ainda assim, a maior parte da amostra, tanto dos policias da Força Tática quanto dos de Rua se recusou na participação e alegação mais comum no grupo, embora esse dado não tenha sido foco de análise, foi o fato de que não se consideravam 'loucos' (expressão utilizada por muitos) e, portanto, não tinham interesse.

Vale esclarecer que este estudo visou levantar dados descritivos, com a finalidade exploratória sobre como os policiais militares percebem sua saúde mental. Os dados relatados por esses profissionais parecem indicar que os mesmos demonstram consciência acerca de sua própria saúde mental. Todavia, conforme já citado anteriormente, esses dados devem ser vistos com cautela, pois também se admite que os participantes podem ter dado respostas socialmente desejáveis por receio de 
alguma complicação futura. Também cabe ressaltar que esses profissionais merecem maior assistência, no sentido da preservação de seu estado emocional e também não se pode deixar de levantar a seguinte questão: É possível diminuir os episódios de excesso de uso da agressividade em razão de atendimentos psicológicos preventivos direcionados a esses profissionais? Tal questão seria pertinente para uma investigação futura.

As corporações militares, de um modo geral, não possuem em seu quadro de funcionários um psicólogo ou até mesmo, um setor de psicologia que atue junto com o médico ou, ainda, que tenha autonomia própria para propor ao militar algum tipo de tratamento ou suporte clínico, ou ainda, algum trabalho preventivo para conter os sintomas mais latentes já no início de seu aparecimento. Essa assistência ocorre, na maior parte das vezes, quando a iniciativa de encaminhamento parte a pedido do militar, o que dificilmente ocorre, devido à preocupação do mesmo com a postura dos demais membros ou quando o policial se envolve em alguma ocorrência e passa a demonstrar problemas decorrentes desta. Diante disso, o militar é afastado de suas funções por determinado período para que seja possível a realização de uma avaliação mais detalhada de seu quadro clínico e psicológico. Esse procedimento, muitas vezes, é considerado pelo policial como uma punição, ou até mesmo como sinal de fraqueza. Percebe-se que, dentro do militarismo não existem medidas preventivas ou políticas públicas efetivas e eficazes que proponham uma melhor estruturação das ações que objetivam a melhoria da qualidade de vida do policial militar.

A presente pesquisa apresentou algumas limitações, sobretudo no que se refere ao tamanho da amostra e também ao fato de que há poucos estudos anteriores que trataram as variáveis aqui investigadas. Também há que se considerar que a presente pesquisa contribui do ponto de vista descritivo e de levantamento exploratório sócio-psicológico do que propriamente se refere a um artigo de defesa de uma posição analítico- 
crítica. Assim sendo, embora a presente pesquisa sirva de base para investigações futuras sobre o tema, é necessário que outros estudos sejam realizados para que se possa buscar e estruturar mecanismos que visem à prevenção dos diferentes fatores que depõem de forma negativa para uma boa saúde física e mental do policial militar.

\title{
The perception of mental health in military police officers of the tactical force and street officers
}

\begin{abstract}
In his work, the military police officer is constantly exposed to situations involving extreme stress. It can result in a state of emotional imbalance. Thus, the purpose of this study is to explore the perception of the military police officers, both the tactical force and the street officers, regarding the aspects that affect their mental health. The participants were 24 military police officers, from two battalions of the Military Police of the state of São Paulo. Those who consented to participate had to answer, individually, 30 questions addressing issues related to the topic. The results showed that the participants $(91.7 \%)$ sometimes, or always, feel stressed; some of them $(41.7 \%)$ reported that they sometimes act on impulse; $88.3 \%$ sometimes, or always, feel emotionally exhausted after a day of work; $62.5 \%$ said they had been aggressive at work; $20.8 \%$ had already considered suicide; and $8.3 \%$ were not satisfied with their jobs. In the end, the authors suggest the need for further studies.
\end{abstract}

Keywords: Emotional fatigue. Physical fatigue. Stress at work. Military police.

\section{Referências}

ASSIS, J. C. Considerações sobre o policial militar da ativa e a prestação de serviços de segurança em horários de folga. Revista Direito Militar da Associação dos Magistrados das Justiças Militares Estaduais, Florianópolis, v. 2, n. 15, p. 8-9, jan./fev. 1999.

BACCARO, A. Vencendo o estresse: como detectá-lo e superá-lo. Petrópolis: Vozes, 1990. 79 p. 
BAPTISTA, M. N.; CAMPOS, D. C. Metodologias de Pesquisa em Ciências. Rio de Janeiro: LTC, 2007.

BENEVIDES-PEREIRA, A. M. T. (Org.). Burnout: quando o trabalho ameaça o bem estar do trabalhador. São Paulo: Casa do Psicólogo, 2002.

BRITO, A. S.; SOUZA, L. Representações sociais de policiais civil sobre profisionalização. Sociologias, v. 6, n. 12, p. 304-327, jul/dez. 2004.

CONSELHO NACIONAL DE SAÚDE. RESOLUÇÃO 196/96. Diretrizes e normas regulamentadoras de pesquisa. Disponível em: <http://www.conselho.saude.gov. br $>$. Acesso em 19 de outubro de 2005.

DEJOURS, C. A loucura do trabalho: estudo de psicopatologia do trabalho. São Paulo: Cortez, 1992.

GASPARINI, D. Direito Administrativo. São Paulo: Saraiva, 2001.

GUIMARÃES, A. F. O contrato de trabalho do policial militar. Revista Direito Milita da Associação dos Magistrados das Justiças Militares Estaduais, Florianópolis, v. 3, n. 17, p. 6-8, mai./jun. 1999.

GUIMARÃES, J. G.; TORRES, A. R. R.; FARIA, M. R. G. V. Democracia e violência policial: o caso da polícia militar. Psicologia em Estudo, v. 10, n. 2, p. 263-271, jul./dez. 2005.

JESUS, F. Psicologia aplicada à justiça. Goiânia: Editora: AB, 2001.

LIPP, M. N. Pesquisas sobre stress no Brasil: saúde, ocupações e grupos de risco. Campinas: Papirus, 1996.

LIPP, M. N.; PEREIRA, M. B.; SADIR, M. A. Crenças irracionais como fontes internas de stress emocional. Revista Brasileira de Terapias Cognitivas, v. 1, n. 1, p. 29-34, jun. 2005.

MARGIS, R.; PICON, P.; COSNER, A. F.; SILVEIRA, R. O. Relação entre estressores, estresse e ansiedade. Revista de Psiquiatria do Rio Grande do Sul, v. 25, (suplemento 1), p. 65-74, abr. 2003.

MINAYO, M. C. S.; Souza, E. R. Missão investigar: entre o ideal e a realidade de ser policial. Rio de Janeiro: Garamond, 2003.

MINAYO, M. C. S.; SOUZA, E. R.; CONSTANTINO, P. Riscos percebidos e vitimização de policiais civis e militares na (in) segurança pública. Cadernos de Saúde Pública, v. 23, n. 11, p. 2767-2779, jan./mar. 2007.

MIRABETE, J. F. Processo Penal. São Paulo: Atlas, 1998. 
PONCIONI, P. O modelo policial profissional e a formação profissional do futuro policial nas academias de polícia do estado do Rio de Janeiro. Sociedade e Estado, v. 20, n. 3, p. 585-610, set./dez. 2005.

PORTO, M. S. G. Polícia e violência: representações sociais de elites policiais do Distrito Federal. São Paulo em Perspectiva, v. 18, n. 1, p. 142-150, jan./mar. 2004.

ROMANO, A. S. P. F. Stress na Polícia Militar: propostas de um curso de controle do stress. In: LIPP, M. E. N. (Org.). Pesquisa sobre estresse no Brasil: saúde, ocupações e grupos de risco. Campinas: Papirus, p.195-210, 1996.

ROSA, P. T. R. Regulamento disciplinar militar e suas inconstitucionalidades. Revista Direito Militar da Associação dos Magistrados das Justiças Militares Estaduais, Florianópolis, v. 5, n. 29, p.16-18, mai./jun. 2001.

SILVA, L. A. M.; LEITE, M. P. Violência, crime e polícia: o que os favelados dizem quando falam desses temas? Sociedade e Estado, v. 22, n. 3, p. 545-591, set./ dez. 2007.

SOUZA, E. R.; FRANCO, L. G.; MEIRELES, C. C.; FERREIRA, V. T.; SANTOS, N. C. Sofrimento psíquico entre policiais civis: uma análise sob a ótica de gênero. Cadernos de Saúde Pública, v. 23, n. 1, p. 105-114, jan./jun. 2007.

SOUZA, E. R.; MINAYO, M. C. S. Policial risco como profissão: morbimortalidade vinculada ao trabalho. Ciência e Saúde Coletiva, v. 10, n. 4, p. 917-928, out./ dez. 2005.

VALLA, W. O. Ética e a atividade do policial militar. Revista Direito Militar da Associação dos Magistrados das Justiças Militares Estaduais, Florianópolis, v. 4, n. 21, p. 5-6, jan./fev. 2000.

VALLA, W. O. O compromisso e as implicações deontológicas para o militar de polícia. Revista Direito Militar da Associação dos Magistrados das Justiças Militares Estaduais, Florianópolis, v. 7, n. 37, p. 10-14, set./out. 2002.

Recebido: 13/09/2008

Aceite final: 20/10/2008 